\title{
Effects of Ammonium Chloride, Salicylate, and Carnitine on Palmitic Acid Oxidation in Rat Liver Slices
}

\author{
VADDANAHALLY T. MADDAIAH AND PAMELA S. MILLER \\ Department of Pediatrics, Nassau County Medical Center and SUNY Stony Brook Health Sciences Center, \\ East Meadow, New York 11554
}

\begin{abstract}
To explore the possible association of hyperlipidemia with hyperammonemia and aspirin ingestion, the effects of $\mathrm{NH}_{4}^{+}$, salicylate, and carnitine on the oxidation of $\left[1-{ }^{14} \mathrm{C}\right]$ palmitic acid to acid-soluble products (ASP) and to $\mathrm{CO}_{2}$ were investigated in rat liver slices. DLcarnitine $(5 \mathrm{mM})$ increased total oxidation $\left(\mathrm{ASP}+\mathrm{CO}_{2}\right)$ more than oxidation to $\mathrm{CO}_{2}$. KCN (1.5 mM) inhibited more than $90 \%$ of the oxidation. $\mathrm{NH}_{4} \mathrm{Cl}$ inhibited the oxidation that reached a maximum at about $40 \mathrm{mM}$, but the inhibition of oxidation to $\mathrm{CO}_{2}(63 \%)$ was larger than that of total oxidation (30\%). Carnitine did not influence $\mathrm{NH}_{4}{ }^{+}$inhibition, which is consistent with the results reported for isolated mitochondria. Salicylate effects depended on salicylate concentration as well as on the presence of carnitine. In the absence of carnitine, inhibition of total oxidation reached $90 \%$ at $3 \mathrm{mM}$ salicylate but that of oxidation to $\mathrm{CO}_{2}$ reached $50 \%$. Velocity calculated at saturating palmitic acid concentration for total oxidation was slightly increased by $0.75 \mathrm{mM}$ salicylate, but the increase for oxidation to $\mathrm{CO}_{2}$ was larger. At $3 \mathrm{mM}$ salicylate, velocity at saturating palmitic acid concentration for the oxidation was decreased, but the decrease for oxidation to $\mathrm{CO}_{2}$ was smaller than for total oxidation. Carnitine partially relieved the inhibition of total oxidation and further increased the formation of $\mathrm{CO}_{2}$. The combination of $20 \mathrm{mM} \mathrm{NH} \mathrm{NCl}_{4}$ and $0.75 \mathrm{mM}$ salicylate inhibited total oxidation, which was more than additive of the individual effects, and carnitine partially relieved the inhibition. It is concluded that $\mathrm{NH}_{4}{ }^{+}$exerted a stronger inhibition of oxidation to $\mathrm{CO}_{2}$ than of oxidation to $\mathrm{ASP}$, whereas salicylate strongly inhibited the oxidation to ASP but increased the oxidation to $\mathrm{CO}_{2}$ by uncoupling mitochondrial oxidative phosphorylation. Therefore, hyperammonemia and aspirin ingestion can inhibit fatty acid oxidation and mitochondrial metabolism that could lead to the pathophysiology seen in some childhood diseases such as Reye's syndrome. Carnitine therapy might offer some benefits. (Pediatr Res 25:119-123, 1989
\end{abstract}

\section{Abbreviations}

RS, Reye's syndrome

ASP, acid soluble products

$V_{s}$, velocity calculated for saturating substrate (palmitic acid) concentration

Received July 25, 1988; accepted September 20, 1988.

Correspondence and reprint requests V. T. Maddaiah, Ph. D., Department of Pediatrics, Nassau County Medical Center, East Meadow, NY 11554.

Supported in part by the American Heart Association. Nassau Chapter. New York. Inc.
Elevation of serum-free fatty acids and fatty infiltration of liver are some of the common pathologic manifestations in children with enzyme defects of the urea cycle (1) and RS (2). Hyperammonemia is also an early laboratory finding in these disease states. It is suggested that the pathophysiology of RS is a metabolic response to an acute injury to mitochondria (3). Among many factors, salicylate, which is the predominant product circulating in blood after ingestion of aspirin, has been implicated in the etiology of RS (4). Salicylate may interfere with the synthesis of high energy phosphates and contribute to mitochondrial degeneration because salicylate uncouples mitochondrial respiration (5), inhibits the activation of fatty acids (6) and induces mitochondrial swelling (7). Similar damaging effects on mitochondria were observed with the serum of RS patients (8, 9 ). In animal model studies of RS, feeding an arginine-deficient diet produced hyperammonemia followed by hyperlipidemia (10). The possible association between hyperammonemia and hyperlipidemia became more apparent when $\mathrm{NH}_{4}{ }^{+}$was found to inhibit the oxidation of fatty acids but not of succinate or malate + glutamate in isolated rat liver mitochondria (11).

The oxidation of fatty acids in liver is important not only for the energy metabolism but also for the clearance of triglycerides and free fatty acids (12). Medium-chain fatty acids are oxidized mostly in mitochondria, whereas long-chain fatty acids are also oxidized in peroxisomes (13). Carnitine is known to function in the transport of medium- and long-chain fatty acids in to mitochondria (14) as well as in some other metabolic processes (15). In view of these findings and that of increased lipolysis after an enhanced release of catecholamines in RS patients (12), a study of the effects of salicylate and $\mathrm{NH}_{4}{ }^{+}$on the oxidation of $\left[1-{ }^{14} \mathrm{C}\right]$ palmitic acid to ASP and $\mathrm{CO}_{2}$ was undertaken in liver slices with and without added carnitine. The results showed that both agents inhibited the oxidation by different degrees, and salicylate inhibition was partially relieved by carnitine.

\section{MATERIALS AND METHODS}

Male Sprague-Dawley rats (250-350 g) were raised in house and maintained on Purina Laboratory Rat Chow (Ralston-Purina, St. Louis, MO) ad libitum. Rats were killed by stunning, followed by decapitation. Livers were quickly removed and placed into ice-cold $\mathrm{Ca}^{2+}$ free Krebs-Ringer phosphate buffer (119 mM NaCl, $4.7 \mathrm{mM} \mathrm{KCl}, 6 \mathrm{mM} \mathrm{MgSO}_{4} \cdot 7 \mathrm{H}_{2} \mathrm{O}$, and 15.5 $\mathrm{mM}$ phosphate buffer, $\mathrm{pH} 7.4$ ). Liver was cut into $1 \mathrm{~cm}^{2}$ pieces, washed, and sliced in a Stadie-Riggs microtome (Thomas Scientific, Swedesboro, NJ) kept cold on ice. Slices 0.1- to 0.2-mm thick were blotted and weighed. Approximately $250 \mathrm{mg}$ of livslices were placed into each of 10-ml Erlenmeyer flasks containing $2 \mathrm{ml}$ of Krebs-Ringer buffer saturated with $99 \% \mathrm{O}_{2}$. Radioactive as well as unlabeled palmitic acid was added as a 5:1 molar complex with BSA (fatty acid free). Salicylate solutions were 
adjusted to $\mathrm{pH}$ 7.4. After all the additions, including $\left[1-{ }^{14} \mathrm{C}\right]$ palmitic acid, were made, the flasks were sealed with rubber stoppers fitted with center well cups containing $0.3 \mathrm{ml}$ of $10 \%$ $\mathrm{KOH}$. The reaction flasks, in duplicate, were incubated in a shaking water bath for $60 \mathrm{~min}$ at $37^{\circ} \mathrm{C}$. The reaction was stopped by adding $0.4 \mathrm{ml}$ of $5 \mathrm{~N}$ perchloric acid and incubated for an additional 45 min to trap all the $\mathrm{CO}_{2}$. Perchloric acid was added before slices in 0 time controls. The reaction mixture was centrifuged, and radioactivity in the supernatant and of the center well cup was measured separately in a liquid scintillation counter (LS-133, Beckman Instruments Inc., Fullerton, CA). After 0 time blank values were subtracted, radioactivity in ASP and $\mathrm{CO}_{2}$ varied from $500-2000$ and from $10,000-75,000 \mathrm{cpm}$, respectively, depending on the concentration of palmitic acid, carnitine, and modifiers. Rate of oxidation was expressed as nmol of palmitic acid oxidized/h/g wt liver. The rate was linear up to 60 min and was proportional to tissue up to $1 \mathrm{~g}$. All chemicals, except BSA fraction V (United States Biochemical Corporation, Cleveland, $\mathrm{OH}$ ), were of reagent grade and purchased from Sigma Chemical Co. (St. Louis, MO). $\left[1-{ }^{14} \mathrm{C}\right]$ palmitic acid $(58 \mathrm{mCi} /$ $\mathrm{mmol}$ ) was purchased from DuPont NEN (Wilmington, DE).

\section{RESULTS}

The oxidation of fatty acids in mitochondria generates acetylCoA which is generally channeled toward ketone body formation and tricarboxylic acid cycle for oxidation to $\mathrm{CO}_{2}$ and $\mathrm{H}_{2} \mathrm{O}$. The completion of the first cycle of $\beta$-oxidation pathway by $\left[1-{ }^{14} \mathrm{C}\right]$ palmitic acid would yield radioactive acetyl-CoA and its metabolites (ketones, tricarboxylic acid cycle intermediates, and possibly some amino acids) (16) which are acid soluble (Fig. 1). Recent studies $(16,17)$ have indicated that the use of $\left[1-{ }^{14} \mathrm{C}\right]$ palmitic acid along with the determination of radioactivity in $\mathrm{CO}_{2}$ as well as in ASP was adequate for an evaluation of fatty acid oxidation in complete tissue preparations. The sum of radioactivity in ASP and $\mathrm{CO}_{2}$, which is presented as total oxidation, would be a measure of the oxidation of palmitic acid to acetyl-CoA, whereas that of $\mathrm{CO}_{2}$ would be a measure of the oxidation of acetyl-CoA in the tricarboxylic acid cycle (Fig. 1). The addition of increasing concentrations of palmitic acid to the incubation medium increased the oxidation to ASP and $\mathrm{CO}_{2}$ (Fig. 2). The rate of oxidation increased with the concentration of DL-carnitine and plateaued at $2-3 \mathrm{mM}$ (not shown). In a patient with methylmalonic aciduria, DL-carnitine was found to be effective in increasing urinary excretion of acylcarnitines but decreasing the excretion of methylmalonate and methylcitrate (18). Although the D-isomer of carnitine is physiologically inactive, it does not appear to affect the transport or other functions of the L-isomer (19). Because whole liver was the tissue of study, $5 \mathrm{mM}$ DL-carnitine was routinely included where indicated. The effective concentration of L-carnitine in the incubation medium would be $2.5 \mathrm{mM}$. Kinetic analysis of these and other data is presented in a later section. Carnitine caused a larger increase in the oxidation to $\mathrm{ASP}+\mathrm{CO}_{2}$ than to $\mathrm{CO}_{2}$ because it decreased the percentage contribution of $\mathrm{CO}_{2}$ to total oxidation from 4.4 \pm 0.9 to $1.7 \pm 0.8(p<0.001$, by Student's $t$ test $)$. The latter value agrees with that reported for liver homogenate from fed rats (16). Because $\mathrm{CO}_{2}$ formation is only a small fraction of ASP $+\mathrm{CO}_{2}$, especially in the presence of carnitine, total oxidation may virtually represent oxidation of palmitic acid to ASP.

Effects of $\mathrm{NH}_{4} \mathrm{Cl}$ and salicylate on oxidation. The concentration of total fatty acids in the serum drawn early in morning from healthy children was found to be $40-60 \mu \mathrm{M}(20)$. Therefore, rates of oxidation were measured at a fixed concentration of 40 $\mu \mathrm{M}$ palmitic acid with varying concentrations of $\mathrm{NH}_{4} \mathrm{Cl}$ and salicylate in the absence and presence of $5 \mathrm{mM}$ DL-carnitine. $\mathrm{NH}_{4} \mathrm{Cl}$ inhibited total oxidation as well as formation of $\mathrm{CO}_{2}$ but the inhibition of the latter was greater (Fig. 3). The inhibition plateaued at about $30 \%$ for total oxidation and at about $63 \%$ for $\mathrm{CO}_{2}$ formation $\left(40 \mathrm{mM} \mathrm{NH}_{4} \mathrm{Cl}\right)$. Consequently, $\mathrm{NH}_{4} \mathrm{Cl}$ decreased

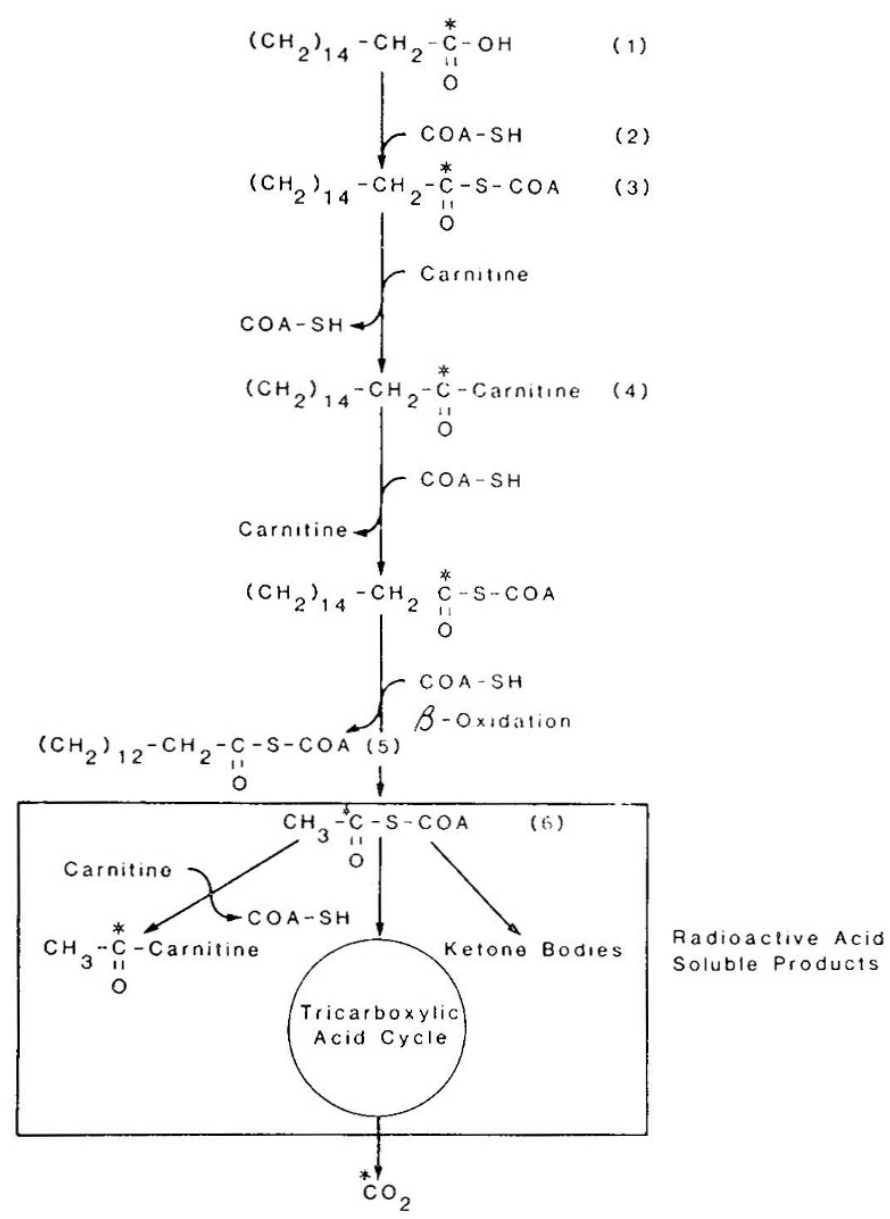

Fig. 1. Pathway for the oxidation of $\left[1-{ }^{14} \mathrm{C}\right]$ palmitic acid $\left({ }^{*} \mathrm{C}={ }^{14} \mathrm{C}\right)$. (1) palmitic acid, (2) $\mathrm{CoASH}$, (3) palmitoyl-CoA, (4) palmitoylcarnitine, (5) myristoyl-CoA, and (6) acetyl-CoA.

the percent contribution of $\mathrm{CO}_{2}$ to total oxidation. The addition of carnitine increased the rate of total oxidation but did not alter the extent of inhibition (Fig. 3).

Effects of varying the concentration of salicylate are shown in Figure 4. The effects on total oxidation and $\mathrm{CO}_{2}$ formation were different and were further modified by carnitine. In the absence of carnitine, steep inhibition of total oxidation occurred which plateaued to about $90 \%$ at $3 \mathrm{mM}$ salicylate (Fig. 4). However, oxidation to $\mathrm{CO}_{2}$ was slightly increased at low concentrations of salicylate $(<0.5 \mathrm{mM})$, beyond which inhibition occurred plateauing to about $55 \%$ at $3 \mathrm{mM}$. In the presence of carnitine, modifying effects depended on the concentration of salicylate (Fig. 4). Up to $0.75 \mathrm{mM}$ salicylate level, total oxidation was either slightly increased or unchanged, but beyond that level, inhibition occurred and increased gradually reaching about $55 \%$ at $3.0 \mathrm{mM}$. The activating effects of low salicylate concentrations and carnitine were most pronounced for $\mathrm{CO}_{2}$ formation than for total oxidation (Fig. 4). For example, the activation of oxidation to $\mathrm{CO}_{2}$ peaked $(180 \%)$ at $0.75 \mathrm{mM}$ salicylate and gradually declined to the $100 \%$ level at $3.0 \mathrm{mM}$. Even $5.0 \mathrm{mM}$ salicylate did not significantly inhibit the $\mathrm{CO}_{2}$ formation.

Effects of $K C N$ on oxidation. Peroxisomal contribution to palmitic acid oxidation in liver slices was evaluated by using $\mathrm{KCN}(1.5 \mathrm{mM})$ as an inhibitor of mitochondrial activity (21) in the absence and presence of modifiers. KCN inhibited total oxidation by 92 and $95 \%$ in the presence and absence of carnitine, respectively (Table 1). Formation of $\mathrm{CO}_{2}$ was almost completely inhibited (not shown). Although the percentage inhibition by $\mathrm{KCN}$ was variable in the presence of $\mathrm{NH}_{4} \mathrm{Cl}$, salicylate, and carnitine, the rate of total oxidation remained constant at a low 


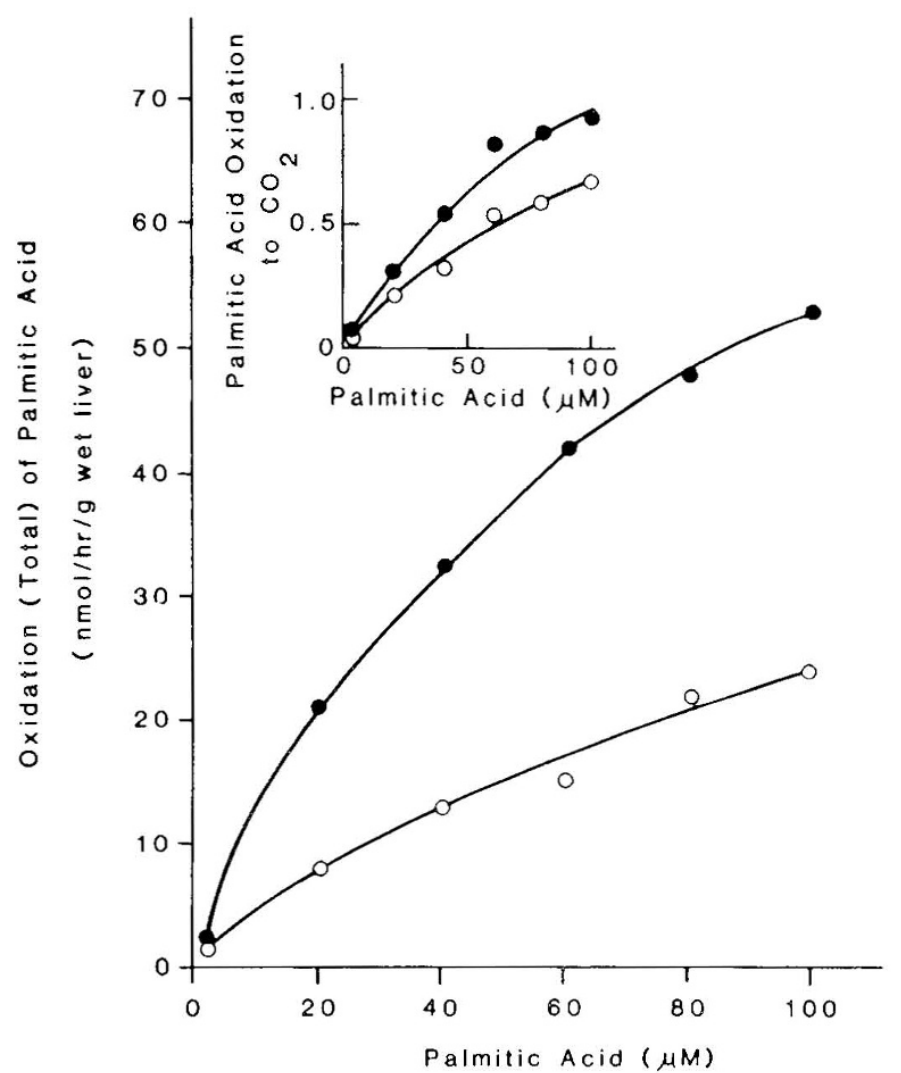

Fig. 2. Oxidation of palmitic acid (added as 5:1 molar complex with albumin) with and without DL-carnitine. Incubations at $37^{\circ} \mathrm{C}$ were carried out as described under experimental procedure. $\mathrm{O}$, without carnitine; with $5 \mathrm{mM}$ DL-carnitine.

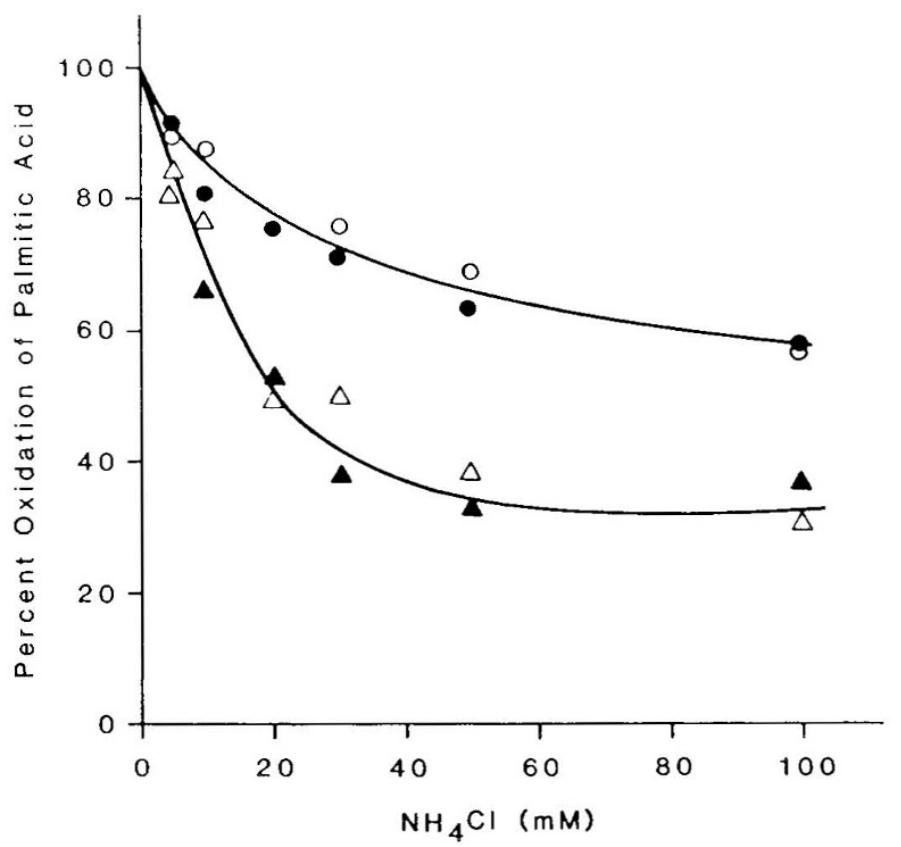

Fig. 3. Effects of varying concentrations of $\mathrm{NH}_{4} \mathrm{Cl}$ on the oxidation of palmitic acid. The concentration of palmitic acid was kept constant at $40 \mu \mathrm{M}$ (5:1 molar complex with albumin). Total oxidation: $\mathrm{O}$, without carnitine: $\bullet$, with $5 \mathrm{mM}$ DL-carnitine; $\triangle$, oxidation to $\mathrm{CO}_{2}$ without carnitine; $\boldsymbol{\Lambda}$. oxidation to $\mathrm{CO}_{2}$ with $5 \mathrm{mM}$ DL-carnitine. Each point is an average of three different experiments. Rates (nmol palmitic acid oxidized $/ \mathrm{h} / \mathrm{g}$ wet liver) in the absence of $\mathrm{NH}_{4} \mathrm{Cl}$ were: total oxidation, 14.6 \pm 2.3 and $33.4 \pm 7.1$ without and with carnitine, respectively, and $0.6 \pm$ 0.1 and $0.7 \pm 0.2$ for oxidation to $\mathrm{CO}_{2}$, respectively.

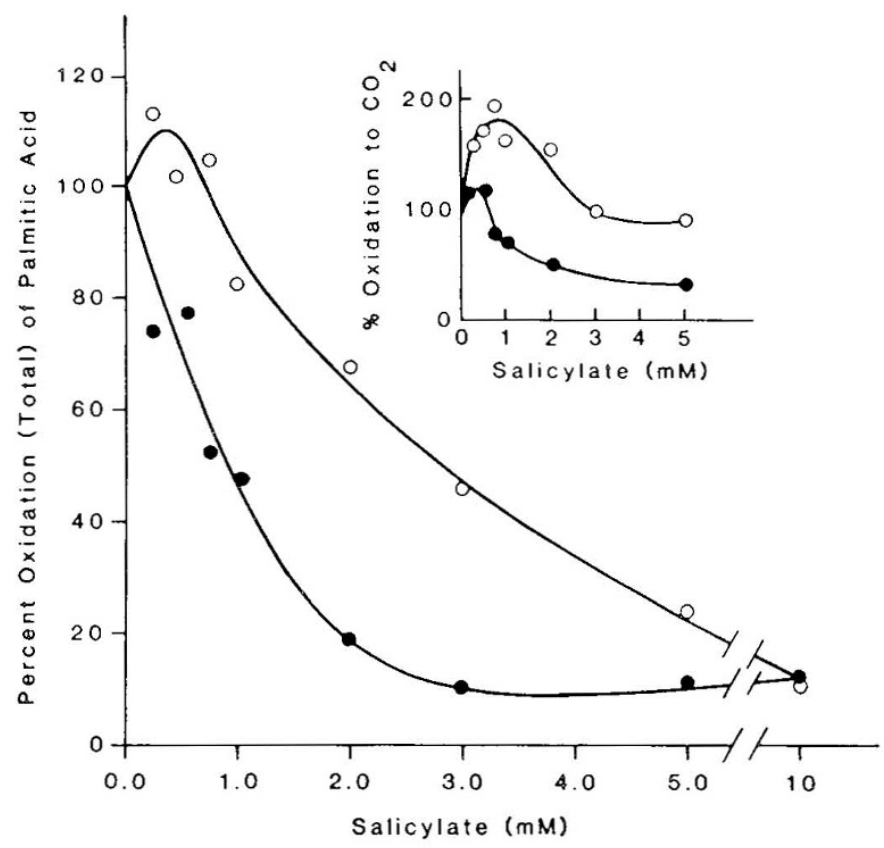

Fig. 4. Effects of varying concentrations of salicylate on the oxidation of palmitic acid. The concentration of palmitic acid was kept at $40 \mu \mathrm{M}$ (5:1 molar complex with albumin). $\bullet$, without carnitine; $\bigcirc$, with $5 \mathrm{mM}$ DL-carnitine. Each point is an average of three different experiments. Rates in the absence of salicylate were similar tc those under Figure 3.

Table 1. Effects of $K C N$ on palmitic acid oxidation in rat liver slices*

\begin{tabular}{|c|c|c|c|c|}
\hline $\begin{array}{c}\text { DL-carnitine } \\
5 \mathrm{mM}\end{array}$ & $\begin{array}{c}\mathrm{NH}_{4} \mathrm{Cl} \\
20 \\
\mathrm{mM}\end{array}$ & $\begin{array}{l}\text { Salicylate } \\
2.0 \mathrm{mM}\end{array}$ & $\begin{array}{c}\mathrm{KCN} \\
1.5 \mathrm{mM}\end{array}$ & $\begin{array}{c}\text { Total } \\
\text { oxidation }\end{array}$ \\
\hline - & - & - & - & 28.1 \\
\hline- & - & - & + & 2.4 \\
\hline+ & - & - & - & 49.3 \\
\hline+ & - & - & + & 2.4 \\
\hline- & + & - & - & 19.5 \\
\hline- & + & - & + & 2.2 \\
\hline+ & + & - & - & 34.8 \\
\hline+ & + & - & + & 3.5 \\
\hline- & - & + & - & 6.2 \\
\hline- & - & + & + & 2.2 \\
\hline+ & - & + & - & 26.8 \\
\hline+ & - & + & + & 3.0 \\
\hline
\end{tabular}

* Incubations were carried out as described in "Materials and Methods," and the concentration of added cold palmitic acid was $80 \mu \mathrm{M}$ (palmitic acid:albumin, 5:1). Rute of oxidation is shown as nmol of palmitic acid/h/g wet liver at $37^{\circ} \mathrm{C}$ and is an average of two different experiments with duplicate incubations.

level $(2-3 \mathrm{nmol})$ that may represent the oxidative activity of peroxisomes under the present experimental conditions.

Effects of modifiers on kinetics. The rate of oxidation increased with the increasing concentration of palmitic acid and tended to follow saturation kinetics (Fig. 2). The addition of modifiers $\left(\mathrm{NH}_{4} \mathrm{Cl}\right.$ and salicylate) did not alter the rate dependence on the concentration but caused inhibition, and the magnitude of their effects were different (not shown). A kinetic analysis was carried out by fitting the data to Lineweaver-Burke equation (22) using the software program ENZPACK (written by PA Williams, Elsevier-BIOSTAT, Cambridge, United Kingdom). The correlation coefficient for a linear fit to the Lineweaver-Burke plot varied from 0.9 to 1 . Although many enzymatic steps are involved in the oxidation of palmitic acid (Fig. 1), calculation of $V_{s}$ should 
prove useful for the purpose of comparison of the effects of different modifiers. Effects of $\mathrm{NH}_{4} \mathrm{Cl}$, salicylate, and carnitine on $\mathrm{V}_{\mathrm{s}}$ are shown in Table 2. Carnitine increased the oxidative utilization from an average of $15 \%$ to $35 \%$ of the added palmitic acid (Fig. 2), and $V_{s}$ for total oxidation was increased 4-fold, whereas the formation of $\mathrm{CO}_{2}$ was only slightly increased.

The addition of $\mathrm{NH}_{4} \mathrm{Cl}(20 \mathrm{mM})$ decreased the $\mathrm{V}_{\mathrm{s}}$ of total oxidation and of $\mathrm{CO}_{2}$ formation, but the inhibition of the latter $(56 \%)$ was larger than that of total oxidation (17\%). Carnitine did not alter the pattern of inhibition, but the magnitude of inhibition of oxidation to $\mathrm{CO}_{2}$ was increased to more than $90 \%$ whereas the inhibition of total oxidation was slightly increased $(27 \%)$. These results confirm the relatively larger inhibition of oxidation to $\mathrm{CO}_{2}$ than to total products by $\mathrm{NH}_{4}{ }^{+}$, as shown in Figure 2.

As shown previously, the modifying effects of salicylate depended on its concentration (Fig. 4). Therefore, kinetic experiments were carried out at low $(0.75 \mathrm{mM})$ and high $(3.0 \mathrm{mM})$ concentrations. In the absence of carnitine, the addition of 0.75 $\mathrm{mM}$ salicylate generally increased the rates (Table 2). However, $V_{\mathrm{s}}$ for oxidation to $\mathrm{CO}_{2}$ was increased by $240 \%$, whereas that of total oxidation was increased by only $163 \%$. The addition of carnitine along with salicylate increased the $\mathrm{V}_{\mathrm{s}}$ for oxidation to $\mathrm{CO}_{2}$ by $170 \%$ over that of carnitine alone, but the $\mathrm{V}_{\mathrm{s}}$ for total oxidation was only slightly increased $(118 \%)$. These results suggest that the maximum capacity for total oxidation was attained in the presence of carnitine alone, whereas that for oxidation to $\mathrm{CO}_{2}$ was attained in the presence of salicylate. At the high salicylate concentration $(3.0 \mathrm{mM}), \mathrm{V}_{\mathrm{s}}$ was decreased by 47 and $92 \%$ for $\mathrm{CO}_{2}$ formation and total oxidation, respectively. In the additional presence of carnitine, the $\mathrm{V}_{\mathrm{s}}$ for $\mathrm{CO}_{2}$ formation was increased by more than $230 \%$ and the $\mathrm{V}_{\mathrm{s}}$ for total oxidation was decreased by $72 \%$ when compared to the presence of carnitine alone. Carnitine has, therefore, altered the modifying action of $3.0 \mathrm{mM}$ salicylate on oxidation to $\mathrm{CO}_{2}$ from inhibition to activation. These results are in agreement with those observed at varying concentrations of $\mathrm{NH}_{4} \mathrm{Cl}$ and salicylate as presented in Figures 3 and 4.

Whether there was any interaction between the modifiers was examined by measuring the kinetics of oxidation in the presence of $20 \mathrm{mM} \mathrm{NH}_{4} \mathrm{Cl}$ and $0.75 \mathrm{mM}$ salicylate (Table 2). The combined presence did not change $\mathrm{V}_{\mathrm{s}}$ for $\mathrm{CO}_{2}$ formation. The inhibitory $\left(\mathrm{NH}_{4} \mathrm{Cl}\right)$ and activating (salicylate) effects may have balanced out in maintaining the $\mathrm{V}_{\mathrm{s}}$ unchanged. However, the com-

Table 2. Effects of carnitine, $\mathrm{NH}_{4} \mathrm{Cl}$ and salicylate on some kinetic parameters of palmitic acid oxidation in rat liver slices*

\begin{tabular}{|c|c|c|c|c|c|c|c|c|}
\hline \multirow[b]{3}{*}{ Modifiers } & \multicolumn{4}{|c|}{ Oxidation to $\mathrm{CO}_{2}$} & \multicolumn{4}{|c|}{ Total oxidation } \\
\hline & \multicolumn{2}{|c|}{$\stackrel{-}{\text { carnitine }}$} & \multicolumn{2}{|c|}{$\stackrel{+}{+}$} & \multicolumn{2}{|c|}{$\stackrel{-}{\text { carnitine }}$} & \multicolumn{2}{|c|}{ 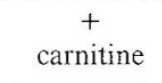 } \\
\hline & $\mathrm{Km}$ & $\mathrm{V}_{\max }$ & $\mathrm{Km}$ & $V_{\max }$ & $\mathrm{Km}$ & $\mathrm{V}_{\max }$ & $\mathrm{Km}$ & $\mathrm{V}_{\max }$ \\
\hline None & 35.1 & 0.71 & 48.3 & 1.20 & 28.8 & 23.90 & 84.4 & 104.0 \\
\hline $\mathrm{NH}_{4} \mathrm{Cl}(20 \mathrm{mM})$ & 32.4 & 0.33 & 88.0 & 0.1 & 73.2 & 19.8 & 135.0 & 75.5 \\
\hline $\begin{array}{l}\text { Salicylate }(0.75 \\
\mathrm{mM})\end{array}$ & 48.9 & 1.71 & 30.7 & 2.04 & 89.7 & 39.1 & 112.0 & 123.0 \\
\hline Salicylate (3 mM) & 80.8 & 0.38 & 12.0 & 2. & 9.9 & & 9 & 29.5 \\
\hline $\begin{array}{l}\mathrm{NH}_{4} \mathrm{Cl}(20 \mathrm{mM})+ \\
\text { salicylate }(0.75 \\
\text { mM) }\end{array}$ & 29.7 & 0.65 & 42.2 & 1.25 & 87.8 & 12.1 & 5.1 & 34.0 \\
\hline
\end{tabular}

* Incubations were carried out as described in "Materials and Methods." The concentration of palmitic acid as 5:1 molar complex with albumin was varied as shown in Figure 2. The data were fitted to the Lineweaver-Burke equation by the software program ENZPACK (Elsevier-Biostat) on an IBM PC-AT (IBM Corp., Danbury, CT). $\mathrm{V}_{\max }$ represents velocity $\left(\mathrm{V}_{\mathrm{s}}\right)$ calculated at saturating substrate concentration, $\mathrm{Km}$ represents the calculated saturating substrate concentration. bined effect on total oxidation (Table 2) was more than the sum of the individual effects on $V_{s}$ because the rate was decreased by 50 and $60 \%$ in the absence and presence of carnitine, respectively.

\section{DISCUSSION}

Identification of the mitochondrion as the site of palmitic acid oxidation is important because previous studies with $\mathrm{NH}_{4}^{+}(11)$ and salicylate (5-9) were done with isolated mitochondria. Strong inhibition of oxidation by $\mathrm{KCN}$ and the absence of carnitine effect on it suggested that palmitic acid was almost exclusively oxidized in mitochondria. Depression of peroxisomal oxidation by $\mathrm{KCN}$ consequent to decreased ATP synthesis cannot be completely excluded. However, production of very low levels of $\mathrm{H}_{2} \mathrm{O}_{2}$ when livers were perfused with palmitic acid indicated that peroxisomal oxidation was negligible (23). Studies of liver homogenates using a variety of inhibitors of mitochondrial oxidation suggested that peroxisomal contribution was less than $10 \%$ (24). Therefore, the observed effects of the modifiers may entirely be due to their actions on mitochondria.

The rates of palmitic acid oxidation and the percentage contribution of $\mathrm{CO}_{2}$ to total oxidation were generally low because the livers were from fed rats (16). Although, the rate of oxidation in liver slices from 24-h fasted rats was higher than those presented here, the effects of $\mathrm{NH}_{4} \mathrm{Cl}$ and salicylate (Maddaiah VT, and Miller PS, unpublished results) were similar. The large and similar activating effect of $5 \mathrm{mM}$ carnitine on the oxidation of palmitic acid to ASP $+\mathrm{CO}_{2}$ was not reflected in a similar increase of oxidation to $\mathrm{CO}_{2}$ in the tricarboxylic acid cycle. The absence of a direct relationship between the oxidation of palmitic acid to acetyl-CoA and to $\mathrm{CO}_{2}$ has been demonstrated in hepatocytes (25) by the use of inhibitors of carnitine-dependent oxidation.

About $60 \%$ of the $\mathrm{O}_{2}$ consumed by hepatocytes during palmitic acid oxidation was found to be associated with acetyl-CoA formation, and the remainder was assumed to represent the oxidation of acetyl-CoA to $\mathrm{CO}_{2}$ and $\mathrm{H}_{2} \mathrm{O}$ in the tricarboxylic acid cycle (25). On the basis of this and the present finding that $\mathrm{NH}_{4}{ }^{+}$ inhibited palmitic acid oxidation to acetyl-CoA, as represented by ASP $+\mathrm{CO}_{2}$, and to $\mathrm{CO}_{2}$ by 30 and $60 \%$, respectively, it is possible to calculate the extent of $\mathrm{NH}_{4}{ }^{+}$inhibition of $\mathrm{O}_{2}$ consumption during palmitic acid oxidation to be about $40 \%$. Indeed, $\mathrm{NH}_{4}{ }^{+}(2 \mathrm{mM})$ inhibited $\mathrm{O}_{2}$ consumption (state 3 respiration) by rat liver mitochondria respiring on palmitoyl-L-carnitine or octanoic acid by $40 \%$ (11). The higher concentration of $\mathrm{NH}_{4} \mathrm{Cl}$ required to exert maximum inhibition in liver slices may be due to low permeability and high metabolism of $\mathrm{NH}_{4}{ }^{+}$. The absence of carnitine influence on inhibition of oxidation to acetyl-CoA supports the previous conclusion (11) that inhibition occurred at step(s) beyond fatty acid transport into mitochondria. The larger inhibition of $\mathrm{CO}_{2}$ formation when compared to ASP $+\mathrm{CO}_{2}$ suggests at least two sites of $\mathrm{NH}_{4}{ }^{+}$inhibition in the pathway of palmitic acid oxidation to $\mathrm{CO}_{2}$. One of the sites is in the $\beta$ oxidation pathway (Fig. 5). Because $\mathrm{NH}_{4}{ }^{+}$inhibited the oxidation of palmitoyl-L-carnitine but not of succinate or malate + glutamate in liver mitochondria (11), respiratory chain as a site of inhibition may be excluded. Therefore, the other inhibitory site may lie in the pathway of utilization of acetyl-CoA in the tricarboxylic acid cycle. A slight inhibition of purified citrate synthase from Crithidia fasciculata, which condenses acetyl-CoA with oxaloacetate, has been reported (26). Larger inhibition of the in vivo enzyme cannot, however, be excluded. Inhibition ofpyruvate oxidation by $\mathrm{NH}_{4}{ }^{+}$in liver mitochondria (Maddaiah VT, and Miller PS, unpublished observations) supports this conclusion. In any event, the effect of $\mathrm{NH}_{4}{ }^{+}$could be compounded because the accumulated fatty acyl-CoA derivatives may inhibit carbamylphosphate synthetase (27) to cause a further rise of blood $\mathrm{NH}_{4}{ }^{+}$level. All these results suggest that $\mathrm{NH}_{4}{ }^{+}$may impede the utilization of acetyl-CoA and decrease energy production in the tricarboxylic acid cycle. Therefore, severe hyper- 


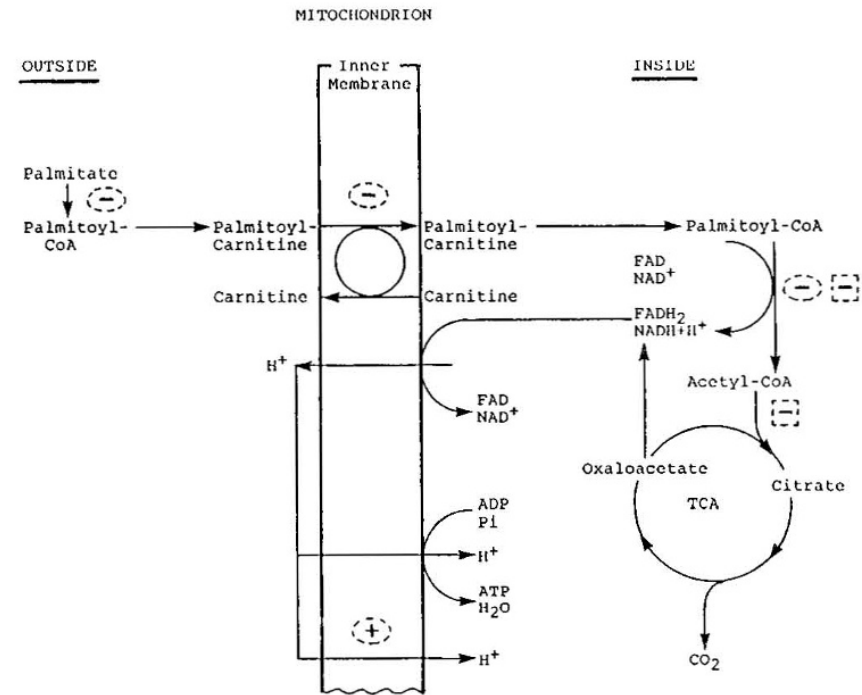

Fig. 5. Effects of $\mathrm{NH}_{4}{ }^{+}$and salicylate on some of the steps in the pathway of oxidation of palmitate and mitochondrial synthesis of ATP. $F A D$, flavin adenine dinucleotide; $N A D$, nicotinamide adenine dinucleotide; $P i$, phosphate; $T C A$, tricarboxylic acid cycle; minus within ellipse, inhibition by salicylate; plus within ellipse, activation by salicylate; minus within square, inhibition by $\mathrm{NH}_{4}{ }^{+}$.

ammonemia may lead to some of the pathophysiology seen in patients with enzyme defects of the urea cycle.

Salicylate exerted inhibitory as well as activation effects at a number of steps in the pathway of palmitate utilization in mitochondrial ATP production (Fig. 5). Generally, oxidation to ASP $+\mathrm{CO}_{2}$ was inhibited, whereas oxidation to $\mathrm{CO}_{2}$ was activated. Such a dual effect is analogous to the actions reported for uncouplers of mitochondrial oxidative phosphorylation (25). Inhibition was relieved by carnitine either completely or partially, depending upon the concentration of salicylate. In view of the well-established role of carnitine (19), one of the inhibitory sites appears to be the transport of palmitoylcarnitine into mitochondria (Fig. 5). As to the mechanism of carnitine effect, the possibility that it may increase salicylate detoxification by esterification exists. However, this appears unlikely because the activating effect of salicylate on $\mathrm{CO}_{2}$ formation was further increased by carnitine. Inhibition of transport would be in addition to that reported for the initial step of fatty acid activation by acyl-CoA ligases (6). Large decreases in the formation of ASP $+\mathrm{CO}_{2}$ in the presence of carnitine but at high concentrations of salicylate suggests that other step(s) in the $\beta$-oxidation pathway may also be inhibited.

The other salicylate effect is uncoupling of oxidative phosphorylation, which is supported by the observations that salicylate decreased protonmotive force and transmembrane potential in isolated liver mitochondria (28). Similar to proton ionophores, salicylate, because of its proton-carrying capacity, can effectively dissipate proton gradient across the inner mitochondrial membrane to by-pass ATP synthesis (Fig. 5). Salicylate can thus increase respiration but decrease ATP synthesis. At low or moderate concentrations, it increases respiration by uncoupling with no or slight inhibition of palmitic acid oxidation to $\mathrm{ASP}+\mathrm{CO}_{2}$. However, at high concentrations of salicylate, severe inhibition of the $\beta$-oxidation pathway as well as swelling (7) may set in, leading to mitochondrial deterioration. The observation of strong inhibitory effect on palmitate oxidation by a combination of
$\mathrm{NH}_{4}{ }^{+}$and moderate concentration $(0.75 \mathrm{mM})$ of salicylate and the partial ameliorating effect by carnitine is of clinical relevance.

Acknowledgment. The authors thank Lisa Schoene for excellent assistance in the preliminary experiments.

\section{REFERENCES}

1. Rosenberg LE, Scriver CR 1980 Disorders of amino acid metabolism. Bondy PK. Rosenberg LE (eds) In: Metabolic Control and Disease. WB Saunders Company, Philadelphia, pp 583-776

2. Reye RDK, Morgan G, Baral J 1963 Encepalopathy and fatty degeneration of the viscera: a disease entity in childhood. Lancet $2: 749-752$

3. Partin JC, Schubert WK, Partin JS 1971 Mitochondrial ultrastructure in Reye's syndrome (encepalopathy and fatty degeneration of the viscera). $\mathrm{N}$ Engl J Med 285-1339-1344

4. Waldman RJ, Hall WN, McGee H, Van Amburg G 1982 Aspirin as a risk factor in Reye's syndrome. JAMA 247:3089-3094

5. Brody TM 1956 Action of sodium salicylate and related compounds on tissue metabolism in vitro. J Pharmacol Exp Ther 117:39-51

6. Yoshida Y, Fuji M, Brown FR III, Singh I 1988 Effect of salicylic acid on mitochondrial-peroxisomal fatty acid catabolism. Pediatr Res 23:338-34

7. Yo KS 1983 Salicylate and mitochondrial injury in Reye's syndrome. Science 220:163-165

8. Asimakis GK, Aprille JR 1977 Reye's syndrome: the effect of patient serum on mitochondrial respiration in vitro. Biochem Biophys Res Commun 79:1122-1129

9. Martens ME, Lee CP 1984 Reye's syndrome: salicylate and mitochondrial functions. Biochem Pharmacol 33:2869-2876

10. Deshmukh DR, Maassab HF, Mason M 1982 Interactions of aspirin and other potential etiologic factors in an animal model of Reye Syndrome. Proc Natl Acad Sci USA 79:7557-7560

11. Maddaiah VT 1985 Ammonium inhibition of fatty acid oxidation in rat liver mitochondria. A possible cause of fatty liver in Reye's syndrome and urea cycle defects. Biochem Biophys Res Commun 127:565-569

12. Kang ES, Gates RE, Wrenn EL Jr 1982 Abnormal cellular regulation of lipolysis and phosphorylation in Reye's Syndrome. Biochem Med 27:180194

13. Lazarow PB 1978 Rat liver peroxisomes catalyze beta-oxidation of fatty acids. J Biol Chem 253:1522-1528

14. Hoppel CL 1982 Carnitine and carnitine palmitoyl transferase in fatty acid oxidation and ketosis. Fed Proc 41:2853-2857

15. Bieber LL, Emaus R, Valkner K, Farrel S 1982 Possible functions of shortchain and medium-chain carnitine acyltransferases. Fed Proc 41:2858-2862

16. Veerkamp JH, Van Moerkerk HTB, Glatz JFC, Zuurveld JGE, Jacobs AEM Wagenmakers AJM $1986{ }^{14} \mathrm{CO}_{2}$ production is no adequate measure of $\left[{ }^{14} \mathrm{C}\right]$-fatty acid oxidation. Biochem Med Metab Biol 35:248-259

17. Chatzidakis C, Otto DA 1987 Labeled oxidation products from $\left[1-{ }^{14} \mathrm{C}\right],\left[\mathrm{U}-{ }^{14} \mathrm{C}\right]$ and $\left[16-{ }^{14} \mathrm{C}\right]$ palmitate in hepatocytes and mitochondria. Lipids 22:620-626

18. Roe CR, Hoppel CL, Stacey CE, Chalmers RA, Tracey BM, Millington DS 1983 Metabolic response to carnitine in methylmalonic aciduria. Arch Dis Child 58:916-920

19. Bremer J 1983 Carnitine-metabolism and functions. Physiol Rev 63:14201480

20. Mamunes P, De Vries GH, Miller CD, David RB 1974 Fatty acid quantitation in Reye's Syndrome. In: Pollack JD (ed) Reye's Syndrome. Grune and Stratton, New York, pp 245-254

21. Lazzarow PB 1981 Assay of peroxisomal beta-oxidation of fatty acids. Methods Enzymol 72:315-319

22. Lehninger AL 1981 Enzyme kinetics and inhibition. In: Biochemistry. Worth Publishers, Inc., New York, pp 183-216

23. Foerster EC, Fahrenkemper T, Graf P, Sies H 1981 Peroxisomal fatty acid oxidation as detected by $\mathrm{H}_{2} \mathrm{O}_{2}$ production in intact perfused liver. Biochem J 196:705-712

24. Mannaerts GP, Debeer LJ, Thomas J. De Schepper PJ 1979 Mitochondrial and peroxisomal fatty acid oxidation in liver homogenates and isolated hepatocytes from control and clofibrate treated rats. J Biol Chem 254:45854595

25. Berry MN, Clark DG, Grivell AR, Wallace PG 1983 The calorigenic nature of hepatic ketogenesis: an explanation for the stimulation of respiration induced by fatty acid substrates. Eur J Biochem 131:205-214

26. Salvarrey MS, Cazzulo JJ 1982 Citrate synthase from Crithidia fasciculata: inhibition by adenine nucleotides and suramin. Comp Biochem Physiol 72:165-168

27. Grusky JA, Rosenberg LE 1974 Inhibition of hepatic mitochondrial carbamyl phosphate synthetase (CPS I) by acyl CoA esters: possible mechanisms of hyperammonemia in the organic acidemias. Pediatr Res 13:475 (abstr)

28. Haas R, Parker Jr WD, Stumpf D, Eguren LA 1985 Salicylate induced loose coupling: protonmotive force measurements. Biochem Pharmacol 34:900 902 